\section{Mapping the Incompatibility and Style Color Loci in Two Hazelnut Progenies}

\author{
Colton Ives, Vidyasagar R. Sathuvalli, Brooke C. Colburn, \\ and Shawn A. Mehlenbacher ${ }^{1}$ \\ Department of Horticulture, 4017 Agricultural and Life Sciences Building, \\ Oregon State University, Corvallis, OR 97331
}

Additional index words. Corylus avellana, filbert, microsatellite, sporophytic, style color

\begin{abstract}
Pollen-stigma incompatibility in european hazelnut (Corylus avellana L.) is of the sporophytic type and under the control of a single locus with multiple alleles (haplotypes). The S-locus was previously assigned to linkage group 5 (LG5) and linked DNA markers were identified. The loci that control leaf color and style color are linked to the S-locus. We investigated segregation for leaf and style color and S-alleles in two progenies, mapped the loci, and compared the two new maps with the LG5 reference map using simple sequence repeat (SSR) markers. Segregation for color, S-alleles and SSR markers fit expectations. The color loci and the S-locus mapped to LG5 between SSR markers B028 and B774. The three maps aligned and the SSR markers were collinear. The SSR markers closest to the S-locus are KG819, KG847, and BR259. In progeny 05050, which segregated for style and leaf color, no recombination was observed between the two traits. Recombination between the S-locus and the style color locus was $5.4 \mathrm{cM}$ in progeny 05050 and $10.1 \mathrm{cM}$ in progeny 00064 . The style color locus was placed very close to SSR marker B028 in both progenies. On the reference map, random amplified polymorphic DNA (RAPD) markers 564-500M, 345-1050dF, and 204-950dF and intersequence simple sequence repeat (ISSR) marker 815-540dF are very close to the S-locus. The identification of closely linked markers will facilitate the map-based cloning of the S-locus and color loci in hazelnut.
\end{abstract}

European hazelnut (Corylus avellana L.), a member of the Betulaceae, is a deciduous shrub native to Europe, Asia Minor, the Caucasus Mountains, and surrounding areas. The major world producers of hazelnuts are Turkey and Italy followed by Azerbaijan, Georgia, U.S., Spain, Iran, China, and France (FAOSTAT, 2011). The United States produces $3 \%$ to $5 \%$ of the world's hazelnuts, $99 \%$ of which are from the Willamette Valley, OR.

Hazelnuts are monoecious, dichogamous, and wind-pollinated. Cross-pollination is enforced by sporophytic incompatibility (Thompson, 1979a, 1979b), which is controlled by a single locus (the S-locus) with multiple alleles (haplotypes). The S-alleles of leading cultivars have been identified and dominance relationships among the alleles determined (Mehlenbacher, 1997a; Mehlenbacher and Thompson, 1988). A total of 33 unique S-alleles have been identified to date (Mehlenbacher, unpublished data). For each allele, a tester genotype whose pollen expresses that allele has been identified.

Received for publication 25 Oct. 2013. Accepted for publication $22 \mathrm{Jan} .2014$.

Funding from the Oregon Hazelnut Commission, State of Oregon, and Hatch Act is acknowledged and appreciated. We thank Patrick Hayes and Alfonso Cuesta-Marcos of the OSU barley project for assistance with JoinMap and MapChart.

A technical paper of the Oregon Agricultural Experiment Station.

${ }^{1}$ To whom reprint requests should be addressed; e-mailmehlenbs@hort.oregonstate.edu.
Hazelnuts are diploid $(2 n=2 x=22)$, and most cultivars are heterozygous at the S-locus. Both alleles are expressed in the stigmas, but often only one is expressed in the pollen because of dominance. The dominance hierarchy is linear with eight levels (Mehlenbacher, 1997a). Fluorescence microscopy is used routinely to identify S-alleles in cultivars and selections (Mehlenbacher, 1997b). The linkage map of Mehlenbacher et al. (2006), constructed using RAPD and SSR markers, placed the S-locus on LG5. ISSR marker 815540 is closely linked to the S-locus (Gürcan et al., 2009).

SSR markers are multiallelic, codominant, and suitable for automated analysis. In addition, primer sequences and data can be shared among laboratories. More than 330 SSR markers have been developed for hazelnut (Bassil et al., 2005a, 2005b; Boccacci et al., 2005; Gürcan et al., 2010a, 2010b; Gürcan and Mehlenbacher, 2010; Peterschmidt, 2013; Sathuvalli and Mehlenbacher, 2013) and the map. SSR markers have been used to fingerprint cultivars and characterize germplasm collections (Bassil et al., 2012; Boccacci et al., 2006, 2008; Gökirmak et al., 2009; Gürcan et al., 2010b; Sathuvalli and Mehlenbacher, 2012).

Thompson (1985) investigated the inheritance of the red pigmentation in leaves. In interspecific populations, segregation ratios were explained by two loci, A and C. However, a single anthocyanin locus (A), with red leaf color dominant to green, is sufficient to explain the 1:1 ratios observed in C. avellana majority have been placed on the linkage populations. The A locus is linked to the incompatibility locus (Thompson, 1985), but the distance between the two loci could not be accurately estimated because of small population sizes.

In C. avellana cultivars, style color ranges from pink to dark purple. Mehlenbacher and Thompson (2004) reported yellow styles in seedlings from a cross of 'Goodpasture' $x$ 'Compton'. Segregation ratios in a series of crosses indicated that style color is controlled by a single locus with red dominant to yellow. Seedlings with yellow styles have green catkins and buds as well as a more upright growth habit when compared with their siblings with red styles. Pedigree analysis indicated that 'Daviana' was the most likely source of the allele for yellow styles. The S-alleles of eight seedlings with yellow styles indicated a possible linkage between the yellow style locus and the S-locus. In a progeny segregating simultaneously for leaf color (red vs. green) and style color, no redleaf seedlings had yellow styles. Mehlenbacher and Thompson (2004) offered two genetic explanations. The first is that the yellow style trait is conferred by an allele $\left(\mathrm{a}^{\mathrm{ys}}\right)$ at the anthocyanin (A) locus that controls leaf color. The second is that there is a style color locus closely linked to the A locus. In either case, the loci would map near the S-locus on LG5.

In this study we recorded style and leaf color and determined the S-alleles in two segregating seedling populations. We fingerprinted the seedlings at SSR loci previously mapped to LG5, constructed linkage maps, and compared them with the previously published reference map to which additional SSR marker loci had been added.

\section{Materials and Methods}

Plant material and DNA extraction. Two progenies (Fig. 1) segregating for style color and S-alleles were used in this study: 91 seedlings of progeny 00064 and 96 seedlings of progeny 05050 (187 seedlings total). Progeny 00064 (designated XE) was from a cross made in 2000 of OSU $372.087\left(\mathrm{~S}_{1} \mathrm{~S}_{11}\right.$, yellow styles) and OSU $704.022\left(\mathrm{~S}_{3} \mathrm{~S}_{26}\right.$, red styles), and segregated for S-alleles and style color. Progeny 05050 (designated BF) was from a cross made in 2005 of OSU 487.044 $\left(\mathrm{S}_{3} \mathrm{~S}_{6}\right.$, red styles, red leaves) and OSU $900.065\left(\mathrm{~S}_{1} \mathrm{~S}_{11}\right.$, yellow styles, green leaves) and segregated for leaf color as well as Salleles and style color. For SSR fingerprinting, 'Barcelona' and 'Daviana' were included as controls. DNA was extracted from fresh leaves as described by Lunde et al. (2000) with no RNase treatment. DNA was extracted from progeny XE in 2005 and from progeny $\mathrm{BF}$ in 2011 and stored in Tris-EDTA buffer at $-18{ }^{\circ} \mathrm{C}$ until used in this study. DNA concentration was determined by a Nanodrop spectrophotometer (NanoDrop, Wilmington, DE) and diluted with Tris-EDTA buffer to a concentration of $20 \mathrm{ng} \cdot \mu \mathrm{L}^{-1}$.

Identification of incompatibility alleles. Seedlings in progeny BF were emasculated 
and bagged in early Dec. 2011 and incompatibility alleles determined using fluorescence microscopy in Feb. 2012 as described in detail by Mehlenbacher (1997b). Seedlings in progeny $\mathrm{XE}$ were handled in the same manner in 2006-07. The pollen testers were 'Barcelona' $\left(\mathrm{S}_{1}\right)$, 'Nonpareil' $\left(\mathrm{S}_{3}\right)$, Henneman \#3 $\left(\mathrm{S}_{6}\right)$, OSU $278.121\left(\mathrm{~S}_{11}\right)$, and OSU $447.015\left(\mathrm{~S}_{26}\right)$. Pollen of the testers was collected in late January to early February and stored at $-18^{\circ} \mathrm{C}$. When styles emerged in mid-February and were receptive, bags were opened and female inflorescences collected using forceps and brought to the laboratory in petri dishes. Pollinations were performed in the laboratory later the same day by holding the female with forceps, dipping the styles into the vial of pollen, tapping the flower on the side of the vial to remove excess pollen, and placing the pollinated flower on a double layer of moist P5 filter paper (Fisher Scientific, Pittsburgh, PA). Extra unpollinated females were stored in the refrigerator in petri dishes lined with moist filter paper and the pollinations repeated if the first results were unclear. The day after pollination, the styles were detached from the buds, squashed in aniline blue dye, and examined at $100 \times$ with a fluorescence microscope under ultraviolet light. Each pollination was scored as compatible or incompatible as described by Mehlenbacher (1997b). In compatible pollinations, pollen germination was excellent and tubes could be seen growing parallel down the style. In incompatible pollinations, germination was often reduced, pollen tubes were short and did not penetrate the stigmatic surface, and the tubes often ended in bulbs. In most cases, the use of fresh, unpollinated female flowers and viable tester pollen made it easy and quick to distinguish the two reactions. A second year of testing was required to identify the S-alleles in seven seedlings of progeny $\mathrm{BF}$.

SSR marker analysis. A total of 20 SSR markers previously assigned to LG5 on the reference map (OSU 252.146 × OSU 414.062) was chosen based on polymorphic information content, ease of scoring, and suitability for multiplexing and used to amplify DNA from the two seedling populations. Three additional SSR loci (A611, B765, and B503) that mapped to LG5 in other populations and the unpublished SSR locus designated SMN_P developed from an internal repeat in an ISSR fragment generated by primer UBC 881 and 'Negret' template DNA as described by Gürcan and Mehlenbacher (2010) were also used. For marker SMN_P, the repeat motif is $(\mathrm{GAT})_{5}$, the forward primer is ACCC AATCCCACAAAGACTG, the reverse primer is TGGCGTCATTTTGAACGTTAT, and the annealing temperature is $60{ }^{\circ} \mathrm{C}$. DNA was amplified using the polymerase chain reaction (PCR) in a $10-\mu \mathrm{L}$ volume containing $0.5 \mu \mathrm{L} \mathrm{M}$ of each primer, $20 \mathrm{ng}$ of template DNA, $0.2 \mathrm{U}$ of Biolase DNA polymerase (Bioline USA, Taunton, MA), $1.5 \mathrm{~mm} \mathrm{MgCl}_{2}$, $120 \mu \mathrm{M}$ each of dATP, dCTP, dGTP, and dTTP, and the $1 \times$ ammonium-based buffer supplied by the manufacturer. One primer in

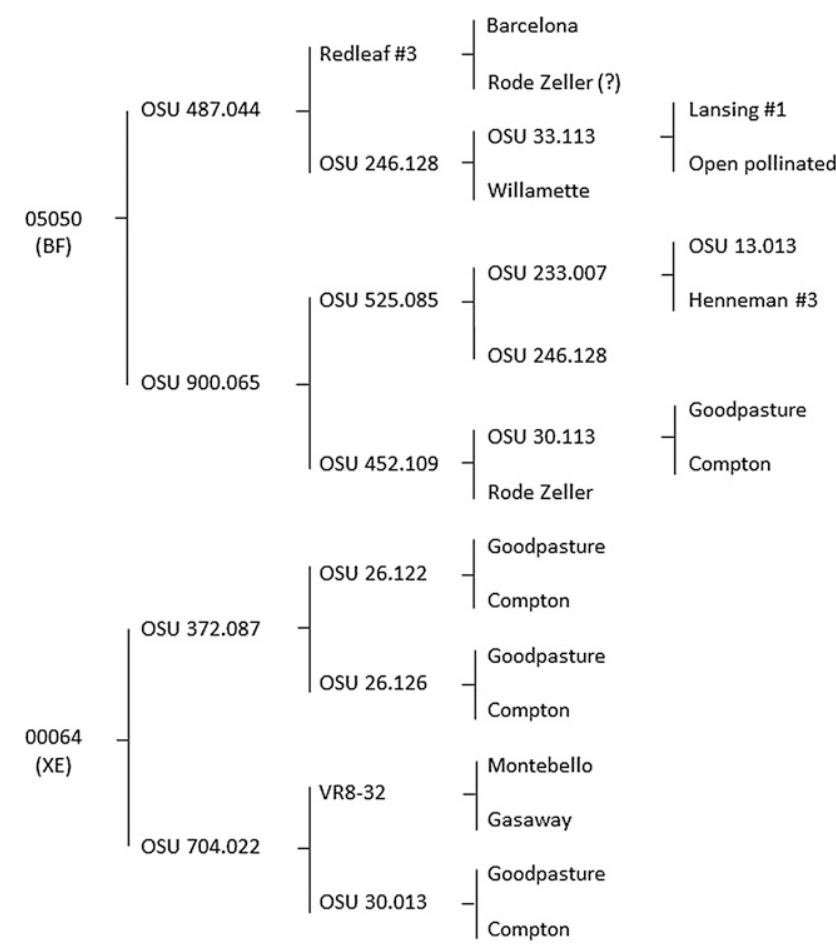

Fig. 1. Pedigrees of two hazelnut progenies segregating for S-alleles, color, and simple sequence repeat markers.

Table 1. Segregation ratios at the S-locus, color loci, and simple sequence repeat markers in two hazelnut progenies. $^{z}$

\begin{tabular}{|c|c|c|c|c|c|}
\hline Locus & Observed & Expected & $\chi^{2}$ & $\mathrm{df}$ & $P$ \\
\hline \multicolumn{6}{|c|}{ Progeny 05050 (BF) } \\
\hline A611 & $18: 27: 18: 31$ & $1: 1: 1: 1$ & 5.49 & 3 & 0.14 \\
\hline SMN_P & $42: 52$ & $1: 1$ & 1.06 & 1 & 0.30 \\
\hline A601 & $45: 47$ & $1: 1$ & 0.04 & 1 & 0.83 \\
\hline B625 & $20: 24: 18: 32$ & $1: 1: 1: 1$ & 4.89 & 3 & 0.18 \\
\hline B765 & $44: 50$ & $1: 1$ & 0.38 & 1 & 0.54 \\
\hline BR190 & $44: 50$ & $1: 1$ & 0.38 & 1 & 0.54 \\
\hline B503 & $42: 52$ & $1: 1$ & 1.06 & 1 & 0.30 \\
\hline BR253 & $40: 50$ & $1: 1$ & 1.11 & 1 & 0.29 \\
\hline B741 & $28: 15: 21: 30$ & $1: 1: 1: 1$ & 6.00 & 3 & 0.11 \\
\hline B028 & $44: 50$ & $1: 1$ & 0.38 & 1 & 0.54 \\
\hline Leaf color & $45: 49$ & $1: 1$ & 0.17 & 1 & 0.68 \\
\hline Style color & $42: 49$ & $1: 1$ & 0.54 & 1 & 0.46 \\
\hline S-locus & $13: 30: 28: 21$ & $1: 1: 1: 1$ & 7.74 & 3 & 0.05 \\
\hline BR259 & $28: 13: 22: 29$ & $1: 1: 1: 1$ & 7.04 & 3 & 0.07 \\
\hline KG819 & $30: 13: 21: 30$ & $1: 1: 1: 1$ & 8.55 & 3 & 0.04 \\
\hline KG847 & $13: 30: 30: 21$ & $1: 1: 1: 1$ & 8.55 & 3 & 0.04 \\
\hline B774 & $15: 28: 30: 21$ & $1: 1: 1: 1$ & 6.00 & 3 & 0.11 \\
\hline B720 & $26: 14: 25: 29$ & $1: 1: 1: 1$ & 5.49 & 3 & 0.14 \\
\hline BR294 & $48: 44$ & $1: 1$ & 0.17 & 1 & 0.68 \\
\hline \multicolumn{6}{|c|}{ Progeny 00064 (XE) } \\
\hline A611 & $19: 25: 18: 28$ & $1: 1: 1: 1$ & 3.07 & 3 & 0.38 \\
\hline C114 & $37: 53$ & $1: 1$ & 2.84 & 1 & 0.09 \\
\hline KG868 & $40: 50$ & $1: 1$ & 1.11 & 1 & 0.29 \\
\hline B765 & $39: 51$ & $1: 1$ & 1.60 & 1 & 0.21 \\
\hline B625 & $39: 51$ & $1: 1$ & 1.60 & 1 & 0.21 \\
\hline SMN_P & $40: 50$ & $1: 1$ & 1.11 & 1 & 0.29 \\
\hline B503 & $40: 50$ & $1: 1$ & 1.11 & 1 & 0.29 \\
\hline BR427 & $36: 52$ & $1: 1$ & 2.91 & 1 & 0.09 \\
\hline B028 & $45: 45$ & $1: 1$ & 0.00 & 1 & 1.00 \\
\hline Style color & $43: 47$ & $1: 1$ & 0.18 & 1 & 0.67 \\
\hline BR259 & $37: 46$ & $1: 1$ & 0.98 & 1 & 0.32 \\
\hline KG819 & $20: 21: 24: 25$ & $1: 1: 1: 1$ & 0.76 & 3 & 0.86 \\
\hline KG847 & $41: 49$ & $1: 1$ & 0.71 & 1 & 0.40 \\
\hline S-locus & $23: 25: 21: 21$ & $1: 1: 1: 1$ & 0.49 & 3 & 0.92 \\
\hline B774 & $23: 29: 20: 18$ & $1: 1: 1: 1$ & 3.07 & 3 & 0.38 \\
\hline B720 & $51: 39$ & $1: 1$ & 1.60 & 1 & 0.21 \\
\hline
\end{tabular}

${ }^{\mathrm{z}}$ Markers are listed in map order. 
each pair was fluorescently labeled with FAM, HEX, or NED to allow post-PCR multiplexing. The thermal cycler program consisted of an initial $4 \mathrm{~min}$ at $95^{\circ} \mathrm{C}$ followed by 40 cycles of $30 \mathrm{~s}$ at $95^{\circ} \mathrm{C}, 40 \mathrm{~s}$ at the optimum annealing temperature, $40 \mathrm{~s}$ at $72{ }^{\circ} \mathrm{C}, 7 \mathrm{~min}$ at $72^{\circ} \mathrm{C}$, and ending with an indefinite hold at $16^{\circ} \mathrm{C}$ until retrieved from the thermal cycler. For each multiplex set, $2 \mu \mathrm{L}$ of labeled PCR product from each primer pair was combined and diluted with autoclaved nanopure water to a final volume of $150 \mu \mathrm{L}$. A $1-\mu \mathrm{L}$ aliquot of the mixture was separated using an ABI 3730 DNA Analyzer (Applied Biosystems, Life Technologies Corporation, Carlsbad, CA) at the Core Laboratories of the Center for Genome Research and Biocomputing at Oregon State University. Fragment analysis was carried out using Peak Scanner ${ }^{\mathrm{TM}}$ Software Version 1.0 (Applied Biosystems, Life Technologies Corporation) to determine allele sizes.

Segregation analysis. Individual alleles at marker loci and the S-locus were scored as present or absent and genotypes entered in a spreadsheet. Leaf color was scored as red or green and style color as red or yellow. Data were subjected to a $\chi^{2}$ goodness-of-fit test. The Yates correction factor was not used (Table 1).

Linkage map construction. Leaf color, style color, incompatibility alleles, and SSR marker data were scored for each seedling in the two populations. JoinMap Version 4.0 software (Van Ooijen, 2006) was used to construct maps for each parent and MapChart software (Kyazma, Wageningen, The Netherlands) was used to draw the maps, as described by Mehlenbacher et al. (2006). The data were initially scored as " $h$ " for the presence of a marker allele or trait, "a" for absence, and "u" for unknown (missing data). For markers linked in repulsion, "dummy variables" allowed integration of coupling and repulsion markers and creation of a single map for each parent of a cross. The $\mathrm{CP}$ function of JoinMap then allowed integration of the maps of the female and male parents, resulting in a single map for each progeny. For the CP function, markers heterozygous in the female parent were scored as 11 or $1 \mathrm{~m}$, and markers heterozygous in the male parent were scored as nn or np. SSR markers that segregated 1:1:1:1 were scored as ee, ef, eg, or fg if three alleles were present or as ac, ad, $\mathrm{bc}$, or bd if four alleles were present at that locus. SSR markers that segregated 1:2:1 were scored as hh, hk, or kk. The SSR markers allowed integration of the female and male maps for each progeny. The same SSR markers, including several recently developed (Gürcan et al., 2010a; Gürcan and Mehlenbacher, 2010; Peterschmidt, 2013) were scored in 138 seedlings of the original mapping population (Mehlenbacher et al., 2006). The two reference maps for LG5 (female and male parents), including several new SSR markers, were merged using JoinMap's CP function. The maps for the three progenies were aligned and the locations of SSR loci, the S-locus, and the color loci compared (Fig. 2).

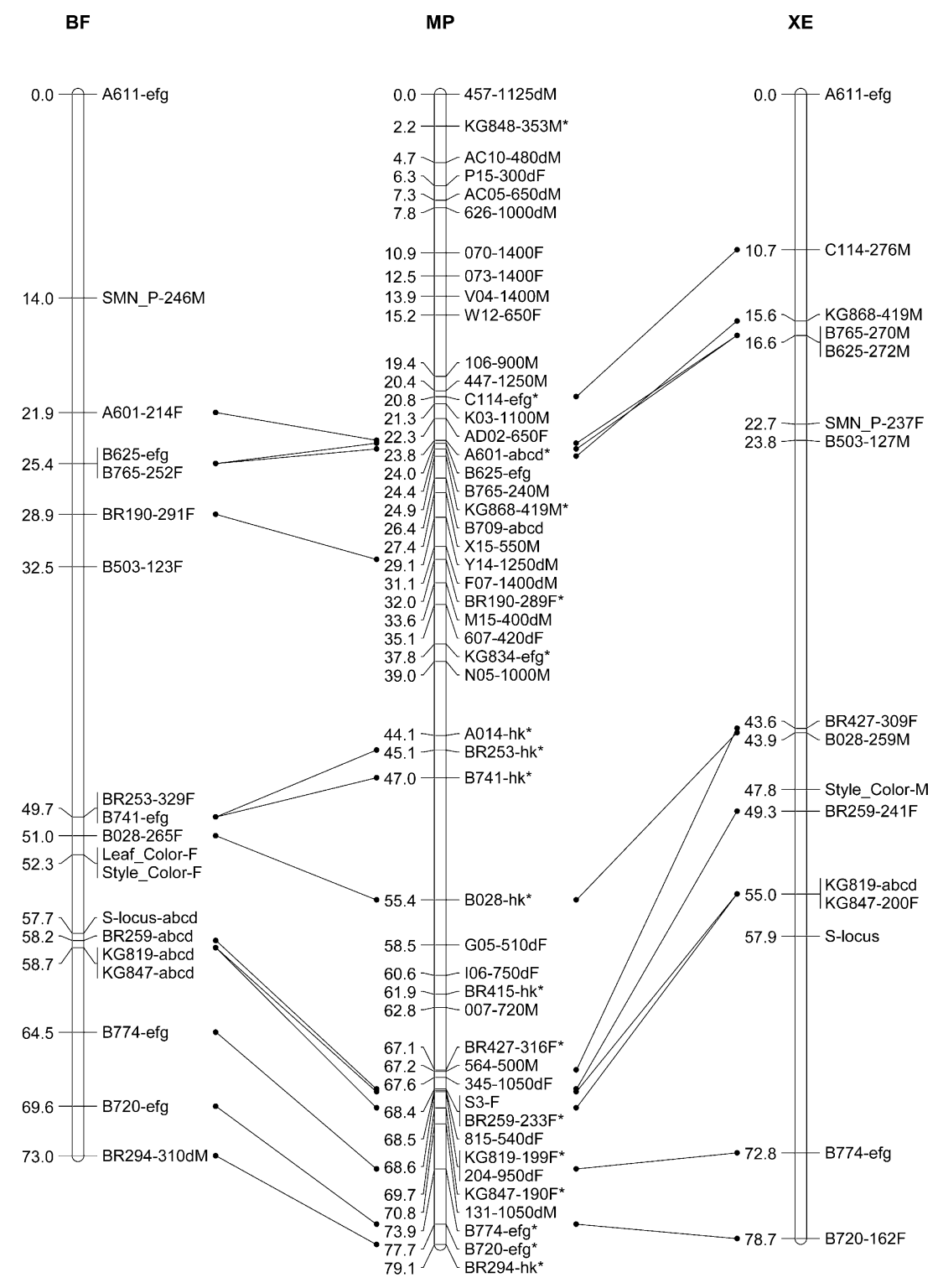

Fig. 2. Maps of linkage group 5 for hazelnut progenies 05050 (BF) and XE 00062 (XE) compared with the reference map. Letter codes at the end of the marker designations indicate markers from the female parent $(\mathrm{F})$ or male parent $(\mathrm{M})$, dummy variables $(\mathrm{d})$, markers that segregate 1:1:1:1 with three loci (efg), markers that segregate 1:1:1:1 with four loci (abcd), and markers that segregate 1:2:1 (hk).

\section{Results and Discussion}

The SSR alleles indicated that two seedlings in each progeny were not from the listed parents. They were removed before further analysis. Not all SSR marker loci segregated in all three progenies, so there was some variation in the loci that could be mapped in each.

In progeny $\mathrm{BF}$, the S-locus, style color, leaf color, and 16 SSR markers were placed on the map. Six markers segregated 1:1 from the female parent $(\mathrm{F})$, two segregated 1:1 from the male parent $(\mathrm{M})$, and eight segregated 1:1:1:1 (efg or abcd) and are shown using the codes of JoinMap's CP function (Table 1). Low probability values for the $\chi^{2}$ test statistics were seen for the S-locus and adjacent markers KG819 and KG847, but all other markers showed good fit. The total map length was $73.0 \mathrm{cM}$ (Fig. 1). SSR markers $\mathrm{KG} 819, \mathrm{KG} 847$, and BR259 were adjacent to the S-locus, and the color locus was $5.4 \mathrm{cM}$ away. No recombination was observed for color of leaves and styles. All seedlings with red leaves also had red styles, and all seedlings with green leaves had yellow styles.

In progeny $\mathrm{XE}$, the S-locus, style color, and 14 SSR markers were placed on the map. Five markers segregated 1:1 from the female parent, six segregated $1: 1$ from the male parent, and three segregated 1:1:1:1 (Table 1). All markers showed good fit to expectation. The total map length was $78.7 \mathrm{cM}$. SSR markers KG819 and KG847 were placed very close to the S-locus, and the style color locus was $10.1 \mathrm{cM}$ away.

Alignment of the maps for progenies BF and XE with the reference map showed that the SSR marker loci were collinear with a few minor changes in order. SSR marker loci $\mathrm{KG} 819, \mathrm{KG} 847$, and BR259 are very close to the S-locus. On the reference map, RAPD 
markers 564-500M, 345-1050dF, and 204950dF and ISSR marker $815-540 \mathrm{dF}$ are also very close to the S-locus. These markers should be useful for map-based cloning of the S-locus. The color loci mapped close to SSR marker B028, 5.4 and $10.1 \mathrm{cM}$ from the S-locus.

\section{Literature Cited}

Bassil, N.V., R. Botta, and S. Mehlenbacher. 2005a. Microsatellite markers in hazelnut: Isolation, characterization and cross-species amplification. J. Amer. Soc. Hort. Sci. 130:543-549.

Bassil, N.V., R. Botta, and S.A. Mehlenbacher. 2005b. Additional microsatellite markers of the european hazelnut. Acta Hort. 686:105110.

Bassil, N.V., J. Postman, K. Hummer, M. Botu, and A. Sezer. 2012. SSR fingerprinting panel verifies identities of clones in backup hazelnut collection of USDA genebank. Acta Hort. 845:95-102.

Boccacci, P., A. Akkak, N.V. Bassil, S.A. Mehlenbacher, and R. Botta. 2005. Characterization and evaluation of microsatellite loci in european hazelnut (Corylus avellana $\mathrm{L}$.) and their transferability to other Corylus species. Mol. Ecol. Notes 5:934-937.

Boccacci, P., A. Akkak, and R. Botta. 2006. DNA typing and genetic relations among european hazelnut (Corylus avellana L.) cultivars using microsatellite markers. Genome 49:598611.

Boccacci, P., R. Botta, and M. Rovira. 2008. Genetic diversity of hazelnut (Corylus avellana L.) germplasm in northeastern Spain. HortScience 43:667-672.
FAOSTAT. 2011. Food and agricultural commodities production. Food and Agriculture Organization of United Nations, Rome, Italy. 28 Dec. 2013. $<$ http://faostat.fao.org/site/339/default.aspx>.

Gökirmak, T., S.A. Mehlenbacher, and N.V. Bassil. 2009. Characterization of european hazelnut (Corylus avellana) cultivars using SSR markers. Genet. Resources Crop Evol. 56:147-172.

Gürcan, K. and S.A. Mehlenbacher. 2010. Development of microsatellite marker loci for european hazelnut (Corylus avellana L.) from ISSR fragments. Mol. Breed. 26:551-559.

Gürcan, K., S.A. Mehlenbacher, R. Botta, and P. Boccacci. 2010a. Development, characterization, segregation, and mapping of microsatellite markers for european hazelnut (Corylus avellana L.) from enriched genomic libraries and usefulness in genetic diversity studies. Tree Genet. Genomes 6:513-531.

Gürcan, K., S.A. Mehlenbacher, and V. Erdoğan. 2010b. Genetic diversity in hazelnut cultivars from Black Sea countries assessed using SSR markers. Plant Breed. 129:422-434.

Gürcan, K., S.A. Mehlenbacher, and V. Cristofori. 2009. Inter-simple sequence repeat (ISSR) markers in hazelnut. Acta Hort. 845:159162.

Lunde, C.F., S.A. Mehlenbacher, and D.C. Smith. 2000. Survey of hazelnut cultivars for response to eastern filbert blight inoculation. HortScience 35:729-731.

Mehlenbacher, S.A., R.N. Brown, E.R. Nouhra, T. Gökirmak, N.V. Bassil, and T.L. Kubisiak. 2006. A genetic linkage map for hazelnut (Corylus avellana L.) based on RAPD and SSR markers. Genome 49:122-133.

Mehlenbacher, S.A. and M.M. Thompson. 2004. Inheritance of style color in hazelnut. HortScience 39:475-476.
Mehlenbacher, S.A. 1997a. Revised dominance hierarchy for S-alleles in Corylus avellana L. Theor. Appl. Genet. 94:360-366.

Mehlenbacher, S.A. 1997b. Testing compatibility of hazelnut crosses using fluorescence microscopy. Acta Hort. 445:167-171.

Mehlenbacher, S.A. and M.M. Thompson. 1988. Dominance relationships among S-alleles in Corylus avellana L. Theor. Appl. Genet. 76:669-672.

Peterschmidt, B.C. 2013. DNA markers and characterization of novel sources of eastern filbert blight resistance in european hazelnut (Corylus avellana L.). MS thesis, Oregon State Univ., Corvallis, OR.

Sathuvalli, V.R. and S.A. Mehlenbacher. 2012. Characterization of american hazelnut (Corylus americana) accessions and Corylus americana $\times$ Corylus avellana hybrids using microsatellite markers. Genet. Resources Crop Evol. 59:10551075.

Sathuvalli, V.R. and S.A. Mehlenbacher. 2013. De novo sequencing of hazelnut bacterial artificial chromosomes (BACs) using multiplex Illumina sequencing and targeted marker development for eastern filbert blight resistance. Tree Genet. Genomes 9:1109-1118.

Thompson, M.M. 1979a. Genetics of incompatibility in Corylus avellana L. Theor. Appl. Genet. 54:113-116.

Thompson, M.M. 1979b. Incompatibility alleles in Corylus avellana cultivars. Theor. Appl. Genet. 55:29-33.

Thompson, M.M. 1985. Linkage of the incompatibility locus and red pigmentation genes in hazelnut. J. Hered. 76:119-122.

Van Ooijen, J.W. 2006. JoinMap® ${ }^{\circledR}$ 4, Software for the calculation of genetic linkage maps in experimental populations. Kyazma B.V., Wageningen, Netherlands. 